\title{
Correction to: Development and Cross-Cultural Validity of a Brief Measure of Separation-Individuation
}

\author{
C. C. Chen $\mathbb{D}^{1} \cdot$ G. B. Richardson ${ }^{2} \cdot$ M. H. C. Lai $^{2}$ - C. L. Dai ${ }^{1}$ - D. G. Hays ${ }^{1}$
}

Published online: 6 July 2018

(c) Springer Science+Business Media, LLC, part of Springer Nature 2018

Correction to: Journal of Child and Family Studies 2018 https://doi.org/10.1007/s10826-018-1140-2

The original version of this article unfortunately contained a mistake. The title was incorrect. The correct title is
"Development and Cross-Cultural Validity of a Brief Measure of Separation-Individuation". The original article has been corrected.

The original article can be found online at https://doi.org/10.1007/ s10826-018-1140-2.

C. C. Chen

ching-chen.chen@unlv.edu

1 University of Nevada, Las Vegas, Las Vegas, NV, USA

2 University of Cincinnati, Cincinnati, OH, USA 